\title{
Review of fall risk assessment in geriatric populations using inertial sensors
}

Jennifer Howcroft ${ }^{1 *}$, Jonathan Kofman ${ }^{1}$ and Edward D Lemaire ${ }^{2,3}$

\begin{abstract}
Background: Falls are a prevalent issue in the geriatric population and can result in damaging physical and psychological consequences. Fall risk assessment can provide information to enable appropriate interventions for those at risk of falling. Wearable inertial-sensor-based systems can provide quantitative measures indicative of fall risk in the geriatric population.

Methods: Forty studies that used inertial sensors to evaluate geriatric fall risk were reviewed and pertinent methodological features were extracted; including, sensor placement, derived parameters used to assess fall risk, fall risk classification method, and fall risk classification model outcomes.

Results: Inertial sensors were placed only on the lower back in the majority of papers (65\%). One hundred and thirty distinct variables were assessed, which were categorized as position and angle (7.7\%), angular velocity (11.5\%), linear acceleration (20\%), spatial (3.8\%), temporal (23.1\%), energy (3.8\%), frequency (15.4\%), and other (14.6\%). Fallers were classified using retrospective fall history (30\%), prospective fall occurrence (15\%), and clinical assessment (32.5\%), with 22.5\% using a combination of retrospective fall occurrence and clinical assessments. Half of the studies derived models for fall risk prediction, which reached high levels of accuracy (62-100\%), specificity (35-100\%), and sensitivity (55-99\%).

Conclusions: Inertial sensors are promising sensors for fall risk assessment. Future studies should identify fallers using prospective techniques and focus on determining the most promising sensor sites, in conjunction with determination of optimally predictive variables. Further research should also attempt to link predictive variables to specific fall risk factors and investigate disease populations that are at high risk of falls.
\end{abstract}

Keywords: Geriatric, Elderly, Older adults, Fall risk, Inertial sensor, Accelerometer, Gyroscope, Wearable sensor

\section{Introduction}

Approximately one third of people over 65 years of age will fall each year [1,2], with the fall rate increasing with age $[3,4]$ and for those in long-term care [5]. Elderly fall related injuries cost $\$ 20$ billion per year in the United States alone [6]. Furthermore, the direct-care costs of fall related injuries could reach $\$ 32.4$ billion per year by 2020 [7].

Falls can result in lasting and critical consequences; including, injury $[3,8]$, long-term disability [9], reduced activity and mobility levels $[4,8,10,11]$, admission to longterm care institutions $[4,10,11]$, fear of falling $[8,11]$, reduced self-confidence in mobility $[4,12]$, and death

\footnotetext{
* Correspondence: jirwin02@gmail.com

'Department of Systems Design Engineering, University of Waterloo, 200

University Avenue West, Waterloo, ON N2L 3G1, Canada

Full list of author information is available at the end of the article
}

$[11,13]$. Fear of falling is a particularly worrisome consequence since fear can lead to a cyclical pattern of mobility deterioration, social isolation, and decreased quality of life, even without a fall occurring [14].

The seriousness of the physical, psychological, and economic consequences of falling has led to two fallmanagement approaches. The first uses physical-monitoring devices to detect falls and signal for immediate care. However, this approach can only reduce consequence severity. The second approach prevents fall occurrence through interventions such as exercise $[15,16]$, improved footwear [15], assistive devices [16], adaptation or modification of the home environment $[15,16]$, review and modification of medication [15], and increased surveillance and care by caregivers [16]. Fall risk assessment is an important and effective prevention tool that identifies

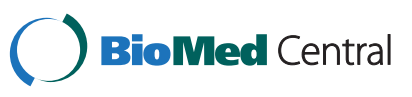


intrinsic (muscle weakness, neurological deficits, etc.) and extrinsic (poor lighting, inappropriate footwear, etc.) risk factors that help determine the most appropriate interventions, and ultimately reduce or eliminate falls [16].

Clinical fall risk assessments often involve questionnaires or functional assessments of posture, gait, cognition, and other fall risk factors [17]. These clinical assessments can be subjective, qualitative $[17,18]$, and use threshold assessment scores to binarily categorize people as fallers and non-fallers. This oversimplifies geriatric fall risk, which is more accurately modeled by a continuum of fall risk with fuzzy boundaries between multiple risk categories, such as low, moderate, and high fall risk. Sensors that measure whole body motion [19], ground reaction forces [20], and electromyographic signals [21] provide objective, quantitative measures for fall risk assessment. However, the associated equipment is typically located in a gait laboratory and requires a time consuming setup that is difficult to practically integrate into typical clinic schedules. This limits the testing location and frequency. A wearable system that can efficiently capture and analyze quantitative mobility data could improve fall risk assessment.

Small wearable sensors can provide movement information during daily-living tasks, performed within realworld environments, instead of the simulated activities used in most clinical assessments. Gyroscopes and accelerometers are inertial sensors that are inexpensive, small, portable, and can be applied in common point-of-care environments or in the community (i.e., outdoors, stairs, ramps, etc.). Inertial sensors directly measure angular velocity and linear acceleration of body segments, from which other body motion parameters can be calculated. Inertial sensors in physical activity-monitoring systems have been used to detect falls, and several review papers summarize advances in this area [13,22-26].

Recently, inertial sensors have been incorporated into fall risk assessment protocols for older adults and could be used to generate input data for intelligent soft computing applications (i.e., methods that consider imprecision and uncertainty in complex system analysis) that represent geriatric fall risk as a continuum. To date, inertial sensor use in fall risk assessment has varied by study methodology, assessment variables, and fall risk models. One of the accelerometer-based physicalactivity-monitoring review papers [26] provided only a brief review of inertial-sensor-based fall risk assessment. Shany et al. [27] provided an interesting discussion of wearable sensors for fall risk assessment, focusing on high-level methodologies when assessing structured or unstructured movements in supervised or unsupervised environments.
For inertial-sensor-based fall risk assessment, a critical and comprehensive examination is still required that addresses study methodologies, assessment activities, sensor locations on the body, measured and derived variables, functional clinical assessment comparators, and fall risk assessment model-validation methods. This paper performs such a critical examination of inertial sensor application for fall risk assessment and identifies important areas for future work.

\section{Search strategy and selection criteria}

A literature review was performed using the key words: "(aged or geriatr* or gerontol* or senior* or elder* or old $^{*}$ ) and (acceler* or inertia* or gyro*) and (fall* or fall risk or fall prediction)" on Web of Science, Scholars Portal, Pubmed, and Google Scholar on March 25 2013. Reference lists from the identified publications were reviewed to identify additional research articles of interest. The results of this search are shown in Figure 1. Paper inclusion criteria included fall risk assessment using inertial sensors, involvement of a geriatric population based on a mean participant age greater than or equal to 60 years, and published in English.

Forty articles from the database searches and article references met the inclusion criteria. Pertinent methodological features were extracted; including, fall risk classification method, sensor placement, activities assessed while inertial sensors were worn, and inertial-based parameters used to assess fall risk. Model assessment outcomes (i.e. accuracy, specificity, and sensitivity [28]) were extracted when available.

\section{Results}

\section{Fall risk classification}

Three main methods were used to classify subjects into faller and non-faller categories: retrospective fall history (30\%), prospective fall occurrence (15\%), and scores on clinical assessments (32.5\%). A combination of retrospective fall history and clinical assessment tools were used to assess fall risk in $22.5 \%$ of the studies. Brief descriptions of the clinical assessment tools are provided in Table 1. Table 2 lists fall risk classification methods used in the literature.

\section{Inertial sensors}

Two different inertial sensors were used in the reviewed papers: gyroscopes (angular velocity) and accelerometers (linear acceleration) [76]. Descriptions of gyroscopes and accelerometers are provided by Webster [76]. Accelerometers were the only inertial sensor in $70 \%$ of the studies, whereas gyroscopes were the only inertial sensor in one study [17]. Both accelerometers and gyroscopes were used in $27.5 \%$ of the studies. 


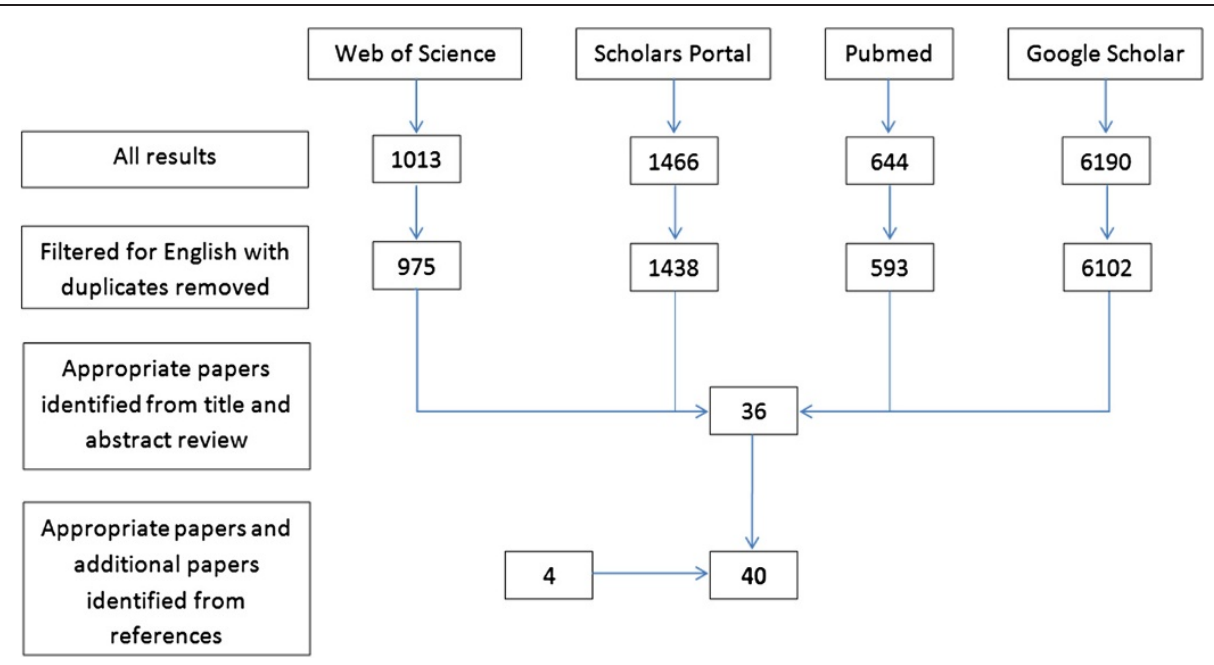

Figure 1 Summary of literature search process.

\section{Sensor location}

Accelerometers and gyroscopes are small enough for measurement during activity, via attachment to a body part, belt, or headband. The lower back, including the pelvis, sacrum, and the L3 to L5 vertebrae, is the most common sensor location and was the only location in $65 \%$ of the studies. This site approximates the center of mass location [46,49,60,61,74] and is acceptable for long-term at-home use [49,61]. Other sensor locations include the head $[18,55,64]$, upper back $[44,73,75]$, sternum $[17,42,45]$, shoulder [41], elbow [41], wrist [41], hip [18,56], thigh [42], knee [41,56], shank [50], ankle $[41,56]$, and foot $[69,71]$.

\section{Assessed activity}

Various activities were used for inertial-sensor-based fall risk assessment. The most frequently assessed activity was level ground walking (45\%), followed by Timed Up and Go (TUG) (32.5\%), sit-to-stand transitions (STS, 22.5\%), standing postural sway (20\%), left-right Alternating Step Test (AST) on level ground (15\%), and uneven-ground walking (2.5\%). Many studies used a combination of activities (20\%). For level walking, subject-selected walking speed was assessed in the majority of studies (66.7\%) while other walking speeds (slow, fast) were assessed in

\section{Table 1 Clinical assessment tools}

\begin{tabular}{|c|c|}
\hline Assessment tool & Description \\
\hline Barthel Index [29] & $\begin{array}{l}\text { Ordinal scale that ranks subjects from } 0 \text { (total dependence) to } 100 \text { (total independence) based on } 8 \text { self-care and } 2 \\
\text { mobility activities of daily living. }\end{array}$ \\
\hline Fried's Frailty Criteria [30] & $\begin{array}{l}\text { Presence of } 3 \text { or more of } 5 \text { frailty indicators (significant and unintentional weight loss, grip weakness, poor } \\
\text { endurance and energy, slow gait speed, low physical activity level). }\end{array}$ \\
\hline Fukuda Test [31] & $\begin{array}{l}\text { The person is blindfolded, extends both arms, and marches in place for } 50 \text { to } 100 \text { steps. Maximum body rotation } \\
\text { greater than } 30^{\circ} \text { indicates vestibular deficits. }\end{array}$ \\
\hline Mini Motor Test [32] & $\begin{array}{l}20 \text { item test that assesses abilities in bed ( } 2 \text { items), sitting position ( } 3 \text { items), standing position ( } 9 \text { items), and gait ( } 6 \\
\text { items). }\end{array}$ \\
\hline One Legged Stance Test [33] & $\begin{array}{l}\text { Time a person can stand on one leg without upper extremity support and without bracing the suspended leg } \\
\text { against the stance leg. Greater than } 30 \mathrm{~s} \text { indicates low fall risk and less than } 5 \mathrm{~s} \text { indicates high fall risk. }\end{array}$ \\
\hline Physical Performance Test [34] & $\begin{array}{l}\text { Ability to stand with feet together side-by-side, semi-tandem, and tandem; walk } 8 \mathrm{ft} \text {; and rise from a chair and } \\
\text { return to seated position. }\end{array}$ \\
\hline $\begin{array}{l}\text { Physiological Profile Assessment } \\
\text { (PPA) [35] }\end{array}$ & $\begin{array}{l}\text { Assessment of vision, peripheral sensation, muscle force, reaction time, and postural sway. Score of } 0-1=\text { mild risk, } \\
1-2=\text { moderate risk, and }>2=\text { high risk of falling. }\end{array}$ \\
\hline STRATIFY Score [36] & $\begin{array}{l}\text { Assessment of } 2 \text { month fall history, mental alteration, frequent toileting, visual impairment, psychotropic } \\
\text { medication use, and mobility issues. Score of }<2 \text { indicates increased fall risk. }\end{array}$ \\
\hline Timed Up and Go (TUG) [37] & $\begin{array}{l}\text { Time to stand up from an armchair, walk } 3 \text { m, turn, walk back to the chair, and sit down again. Times that exceed } \\
14 \text { s indicate increased fall risk for community dwelling elderly without neurological disorders. }\end{array}$ \\
\hline Tinetti Assessment Tool [38] & $\begin{array}{l}\text { Dynamic balance and gait evaluation with } 10 \text { balance components and } 8 \text { gait components. Overall scores } \\
<19=\text { high fall risk, } 19-23=\text { moderate fall risk, }>23=\text { low fall risk. Maximum score }=40 \text {. }\end{array}$ \\
\hline
\end{tabular}


Table 2 Criterion classification methods used to assess inertial-sensor-based fall risk measures

\begin{tabular}{|c|c|c|c|}
\hline & Retrospective history & Prospective occurrence & Assessment tools \\
\hline Auvinet et al., 2003 [39] & 1 year & - & - \\
\hline Bautmans et al., 2011 [40] & 6 months & - & TUG $>15$ s or Tinetti score $\leq 24$ \\
\hline Caby et al., 2011 [41] & 1 year & - & $\begin{array}{l}25 \text { m walking, Mini Motor test, Tinetti test, } \\
\text { TUG, Physical Performance Scale, Fukuda test, } \\
\text { One Legged Stance test }\end{array}$ \\
\hline Cho and Kamen 1998 [18] & 1 year & - & Self-reported frequent fallers \\
\hline Doheny et al., 2011 [42] & 5 years & - & $\begin{array}{l}\text { Self-reported fear of falling or presence of } \\
\text { cardiovascular risk factors }\end{array}$ \\
\hline Doheny et al., 2012 [43] & 5 years & - & - \\
\hline Doi et al., 2013 [44] & - & 1 year (reported weekly) & - \\
\hline Ganea et al., 2011 [45] & - & - & Fried's criteria for frailty \\
\hline Giansanti et al., 2006, 2008 [46-48] & Unspecified & - & Tinetti test level 3 \\
\hline Gietzelt et al., 2009 [49] & - & - & STRATIFY score (includes 2 month fall history) $\geq 2$ \\
\hline Greene et al., 2010, 2012 [50,51] & 5 years & - & - \\
\hline Ishigaki et al., 2011 [52] & - & - & $\begin{array}{l}\text { One Legged Stance test (eyes open) } \leq 15 \mathrm{~s} \\
\text { and/or TUG } \geq 11 \mathrm{~s}\end{array}$ \\
\hline Kojima et al., 2008 [53] & 1 year & - & - \\
\hline Laessoe et al., 2007 [54] & - & $\begin{array}{l}1 \text { year (fall diary with contact } \\
\text { at } 6 \text { months) }\end{array}$ & - \\
\hline Latt et al., 2009 [55] & 1 year & - & - \\
\hline Liu et al., 2008 [56] & Unspecified & - & $\begin{array}{l}\text { Falling during gait perturbation assessment, } \\
\text { medical history, self-identification as frequent } \\
\text { faller }\end{array}$ \\
\hline Liu et al., 2011 [57] & - & - & PPA \\
\hline Liu et al., 2011 [58] & 1 year & - & - \\
\hline Marschollek et al., 2008 [59] & - & - & $\begin{array}{l}\text { TUG }>20 \text { s, STRATIFY score }>2 \text {, Barthel Index: } \\
\text { Mobility score }<10\end{array}$ \\
\hline Marschollek et al., 2009 [60] & In-hospital history & - & - \\
\hline Marschollek et al., 2011 [61,62] & - & 1 year & - \\
\hline Martinez-Ramirez et al., 2011 [63] & - & - & $\begin{array}{l}\text { Body mass loss } \geq 4.5 \mathrm{~kg} \text {, low energy, low } \\
\text { physical activity, weakness, slowness }\end{array}$ \\
\hline Menz et al., 2003 [64] & - & - & $\begin{array}{l}\text { Overall fall risk score (low, moderate, high } \\
\text { risk) based on vision, peripheral sensation, } \\
\text { strength, reaction time, balance tests }\end{array}$ \\
\hline Moe-Nilssen et al., 2005 [65] & 1 year & - & - \\
\hline Najafi et al., 2002 [17] & - & - & $\begin{array}{l}\text { Fall risk score } \geq 5 \text { based on balance, gait, } \\
\text { visual, cognitive and depressive disorders, } \\
\text { history of falls. }\end{array}$ \\
\hline Narayanan et al., 2008, 2009, 2010 [66-68] & - & - & PPA \\
\hline O'Sullivan et al., 2009 [1] & 1 year & - & - \\
\hline Paterson et al., 2011 [69] & - & 1 year (reported monthly) & - \\
\hline Redmond et al., 2010 [70] & - & - & PPA \\
\hline Schwesig et al., 2012 [71] & - & 1 year (recorded by caregivers) & - \\
\hline Senden et al., 2012 [72] & - & - & Tinetti test $\leq 24$ (Low risk 19-24, High risk <19) \\
\hline Toebes et al., 2012 [73] & 1 year & - & - \\
\hline Weiss et al., 2011 [74] & 1 year & - & - \\
\hline Yack and Berger [75] & 1 year & - & $\begin{array}{l}\text { Self report of unsteady or unstable walking } \\
\text { and/or standing }\end{array}$ \\
\hline
\end{tabular}


$26.7 \%$ of studies and a designated speed was assessed in one study [73].

\section{Variables}

One hundred and thirty distinct variables were assessed in the literature, and can be categorized as: position and angle (7.7\%), angular velocity (11.5\%), linear acceleration (20\%), spatial (3.8\%), temporal (23.1\%), energy (3.8\%), frequency (15.4\%), and other (14.6\%). All variables that had significant outcomes $(\mathrm{p}<0.05)$, together with sensor body locations, are presented in Table 3.

Of the variables that were assessed in more than one study, only 13 were significant $(\mathrm{p}<0.05)$ each time they were assessed: 1) mediolateral and anteroposterior postural sway length $[43,51]$; 2) mediolateral and anteroposterior postural sway velocity $[43,51]$; 3) ratio of mean squared modulus for postural sway [46-48]; 4) standard deviation of anteroposterior acceleration [18,74]; 5) root mean square amplitude of vertical linear acceleration $[55,72]$; 6) gait speed $[40,44,55,64,72,74]$; 7) sit-to-stand transition duration $[17,45]$; 8) dominant Fast Fourier Transform (FFT) peak parameters derived from lowerback linear acceleration signals $[59,61,62]$; 9) ratio of even to odd harmonic magnitudes derived from head, upper back, and lower-back linear acceleration signals $[44,55,57,58,64,72,75]$; 10) area under the first six harmonics divided by the remaining area for lower-back linear acceleration signals $[57,58]$; 11) ratio of the first four harmonics to the magnitude of the first six harmonics for lower-back linear acceleration signals [57,58]; 12) maximum Lyapunov exponent of angular velocity signal [73,77]; 13) discrete wavelet transform parameters from lower-back angular velocity and linear acceleration signals and sternum linear acceleration signals [45,63]. Six of these multi-study variables $(1,2,5,6,9,12)$ were from different research groups, while seven variables $(3,4,7,8,10,11,13)$ were from a single research group.

Mediolateral and anteroposterior postural sway length and velocity are measures of postural stability that represent trunk movement during static standing $[43,51]$. The root mean square of vertical linear accelerations has been used to measure gait smoothness, with larger values linked to increased fall risk [55,72]. Low gait speed has been identified in the broader literature as an indicator of fall risk [77,78]; however, adoption of a low gait speed may also be an accommodation linked to fear of falling and not an indicator of high risk of falling [79]. The ratio of even to odd harmonics of linear acceleration reflects the proportion of the acceleration signal that is in phase with the participant's stride frequency, with even harmonics correlating with in-phase components and odd harmonics correlating with out-of-phase components [55,75]. The area under the first six harmonics divided by the remaining area under the magnitude spectrum curve of the lower-back linear accelerations provides a quantification of gait periodicity $[57,58]$, and the ratio of the first four harmonics to the magnitude of the first six harmonics for lower-back linear accelerations indicates the pattern of harmonic magnitudes [58]. The maximum Lyapunov exponent of angular velocity reflects local dynamic stability [56,73] and converts time series measurements into a state space [73]. In the state space, the Lyapunov exponents measure the average rate of expansion or contraction of the original trajectory in response to perturbations. Larger Lyapunov exponent values indicate a decreased ability to compensate for local perturbations during gait, increased instability, and increased fall risk $[56,73]$.

A wide range of variables have been incorporated into fall risk classification models. Variables that achieved high fall risk classification sensitivity and specificity (i.e., greater than or equal to $80 \%$ ) are discussed here. Successful single-variable models used: 14) the mean squared modulus ratio for postural sway derived from lower back angular velocity [46-48], 15) sit-to-stand transition duration determined from sternum acceleration and angular velocity [45], 16) sit-to-stand fractal dimension derived from sternum acceleration and angular velocity [45], and 17) sit-to-stand lower back jerk (derivative of acceleration) [74]. The mean squared modulus ratio for postural sway is the ratio of the rotational kinematic energy during eyes-open or closed postural sway on a foam surface, to the rotational kinematic energy during eyesopen postural sway on a firm surface [46-48]. The sit-to-stand fractal dimension represents the regularity of the sit-to-stand movement, with larger values associated with greater movement irregularity and fall risk [45].

Several multi-variable models also achieved sensitivity and specificity levels greater than or equal to $80 \%$. One model included 18) pelvic sway and 19) kinetic energy [49]. Caby et al., 2011 [41] investigated a variety of single-variable and multi-variable models derived from accelerometers on the knee, ankle, shoulder, elbow, and wrist. These variables included correlation between left and right elbow accelerations, step frequency, jerk, spectral entropy, acceleration frequency parameters, and $25 \mathrm{~m}$ walk time normalized to participant height. Liu et al., 2011 [57] developed a multi-variable model that included 126 temporal, energy, and frequency variables derived from TUG, STS, and AST movements.

\section{Classification models of fall risk prediction}

In half of the papers, geriatric fall risk was predicted using derived models (50\%), as opposed to correlating a variable with fall risk or fall occurrence. Regression 
Table 3 Significant inertial-sensor-based variables $(p<0.05)$ with associated sensor location

\begin{tabular}{|c|c|c|}
\hline Category & Variable & Sensor location \\
\hline \multirow{5}{*}{$\begin{array}{l}\text { Position and Angle } \\
\text { Variables }\end{array}$} & AP peak to peak amplitude & LB [52] \\
\hline & ML peak to peak amplitude & LB [52] \\
\hline & $\checkmark$ peak to peak amplitude & LB [52] \\
\hline & $\mathrm{AP}$ and ML postural sway length during stance & LB $[43,51]$ \\
\hline & Trunk tilt & St [44] \\
\hline \multirow{13}{*}{$\begin{array}{l}\text { Angular Velocity } \\
\text { Variables }\end{array}$} & Min, mean, max AP & Sha [50] \\
\hline & Min, mean, max ML & Sha [50] \\
\hline & Min, mean, $\max V$ & Sha [50] \\
\hline & AP peak to peak amplitude & LB [52] \\
\hline & ML peak to peak amplitude & Sha [50] \\
\hline & $\checkmark$ peak to peak amplitude & LB [52] \\
\hline & Postural sway velocity during stance & $\operatorname{LB}[43,51]$ \\
\hline & Mean squared modulus ratio for postural sway & LB [46-48] \\
\hline & AP RMS during stance & LB [51] \\
\hline & ML RMS during stance & LB [51] \\
\hline & V RMS during stance & LB [51] \\
\hline & 3D RMS during stance & LB [51] \\
\hline & ML variability & UB [73] \\
\hline \multirow{22}{*}{$\begin{array}{l}\text { Linear Acceleration } \\
\text { Variables }\end{array}$} & Median AP & LB [74] \\
\hline & SD of AP & He [18], LB [74], Hi [18] \\
\hline & Peak AP & UB [75] \\
\hline & Peak V & UB [75] \\
\hline & AP peak to peak amplitude & LB [52] \\
\hline & ML peak to peak amplitude & LB $[49,52,60]$ \\
\hline & $\checkmark$ peak to peak amplitude & LB [52] \\
\hline & AP RMS & $\mathrm{He}[55], \mathrm{LB}[55]$ \\
\hline & ML RMS & $\mathrm{He}[55], \mathrm{LB}[55]$ \\
\hline & V RMS & He [55], LB [55,71] \\
\hline & AP RMS during stance & LB [51] \\
\hline & ML RMS during stance & LB [51] \\
\hline & V RMS during stance & LB [51] \\
\hline & 2D RMS (ML and AP) during stance & LB [43] \\
\hline & 3D RMS & LB $[1,57]$ \\
\hline & 3D RMS during stance & LB [51] \\
\hline & Jerk & St [42] \\
\hline & Sit to stand AP range & LB [74] \\
\hline & Stand to sit AP range & LB [74] \\
\hline & Sit to stand Jerk & LB [74] \\
\hline & Dissimilarity of AST subcomponents & LB $[57,67]$ \\
\hline & Dissimilarity of STS subcomponents & LB $[67,68,70]$ \\
\hline \multirow[t]{2}{*}{ Spatial Variables } & Number of steps & LB [60], Sha [50] \\
\hline & Step length & He [64], LB [60,64,72] \\
\hline \multirow[t]{2}{*}{ Temporal Variables } & Gait Speed & He [55,64], LB $[40,44,55,64,72,74]$ \\
\hline & Cadence & He [64], LB [39,58,64], Kn [41], Sha [50], An [41] \\
\hline
\end{tabular}


Table 3 Significant inertial-sensor-based variables $(\mathbf{p}<0.05)$ with associated sensor location (Continued)

\begin{tabular}{|c|c|c|}
\hline & Step duration & LB [74], Sha [50] \\
\hline & Step duration variability & $\mathrm{He}[55], \mathrm{LB}[55]$ \\
\hline & Stride time & Fo [71] \\
\hline & SD of stride time & Fo [71] \\
\hline & $\%$ GC double support & Sha [50] \\
\hline & TUG time & LB $[66,74]$, Sha $[50]$ \\
\hline & TUG subcomponent time & LB $[57,66]$, Sha $[50]$ \\
\hline & TUG: number of gait cycles & Sha [50] \\
\hline & STS time & LB [66] \\
\hline & STS subcomponent times & LB [57], Th [42] \\
\hline & SD of STS subcomponent times & LB [66] \\
\hline & Normalized SD of STS subcomponent times & LB $[58,66]$ \\
\hline & Sit/stand transition duration & St $[17,45]$ \\
\hline & Sit/stand SD of transition duration & St [17] \\
\hline & AST time & LB [66] \\
\hline & AST subcomponent times & LB $[57,58,68,70]$ \\
\hline & SD of AST subcomponent times & LB [66] \\
\hline & Normalized SD of AST subcomponent times & LB $[67,68,70]$ \\
\hline Energy Variables & Kinetic Energy & LB [49] \\
\hline & Local wavelet energy & St [45] \\
\hline & Summed magnitude area of acceleration & LB $[57,58,67]$ \\
\hline & $25 \%$ quartile frequency & $\mathrm{He}[18], \mathrm{Hi}[18]$ \\
\hline & $50 \%$ quartile frequency & $\mathrm{He}[18], \mathrm{Hi}[18]$ \\
\hline & $75 \%$ quartile frequency & $\mathrm{He}[18], \mathrm{Hi}[18]$ \\
\hline & Sway frequency during stance & LB [51] \\
\hline & Number of FFT peaks & LB $[61,62]$ \\
\hline & Dominant FFT peak parameters & LB $[59,61,62]$ \\
\hline & $1^{\text {st }}$ FFT peak parameters & Sho [41], El [41], Wr [41], Kn [41], An [41] \\
\hline & Ratio of magnitude of even harmonics to odd harmonics & $\mathrm{He}[55,64], \mathrm{UB}[44,75], \mathrm{LB}[44,50,52,53,59,72]$ \\
\hline & Area under $1^{\text {st }} 6$ harmonics divided by remaining area & $\operatorname{LB}[57,58]$ \\
\hline & Ratio of $1^{\text {st }} 4$ harmonics to magnitude of $1^{\text {st }} 6$ harmonics & LB $[57,58]$ \\
\hline & ML spectral edge frequency & St [42] \\
\hline & Entropy of power spectrum & LB [53] \\
\hline & Correlation between left and right arm signals & Sho [41], El [41], Wr [41] \\
\hline & Maximum $V$ acceleration Lyapunov Exponent & Hi [56], Kn [56], An [56] \\
\hline & Maximum AV Lyapunov Exponent & UB [73], Hi [56], Kn [56], An [56] \\
\hline & Autocorrelation coefficients of acceleration signal & $\operatorname{LB}[39,65]$ \\
\hline & Trunk level forces & St [45] \\
\hline & Continuous wavelet transform & LB [63] \\
\hline & Discrete wavelet transform & St [45], LB [63] \\
\hline & $\begin{array}{l}\text { Detrended fluctuation fractal scaling index of acceleration } \\
\text { derived stride time }\end{array}$ & Fo [69] \\
\hline
\end{tabular}


Table 3 Significant inertial-sensor-based variables $(\mathbf{p}<\mathbf{0 . 0 5 )}$ with associated sensor location (Continued)

$\begin{array}{ll}\text { Fractal dimension of acceleration versus AV } & \text { St [45] } \\ \text { Number of abnormal sit/stand transitions } & \text { St [17] }\end{array}$

$A n$, ankle, $A P$, anteroposterior, $A S T$, Alternating Step Test, $A V$, angular velocity, COP, center of pressure, CoV, coefficient of variation, El, elbow, $F F T$, Fast Fourier Transform, Fo, foot, He, head, Hi, hip, GC, gait cycle, Kn, knee, LB, lower back, ML, mediolateral, RMS, Root Mean Square, SD, standard deviation, Sha, shank, Sho, shoulder, St, sternum, STS, sit-to-stand transitions, Th, thigh, TUG, Timed Up and Go, UB, upper back, $V$, vertical, Wr, wrist.

models (65\%), mathematical classifiers (25\%), decision trees (15\%), neural networks (15\%), support vector machines $(10 \%)$, and cluster analysis (10\%) were employed to predict fall risk, with some studies using more than one method (30\%). The accuracy, specificity, and sensitivity [28] of these models are shown in Table 4.

\section{Discussion}

Wearable inertial sensors are a viable technology for fall risk assessment, joining clinical and laboratory methods as acceptable assessment tools. Inertial-sensor-based systems have the benefits of portability, low cost, and few constraints on the types of movements that can be

Table 4 Fall-risk assessment model type, validation method, accuracy, specificity, and sensitivity

\begin{tabular}{|c|c|c|c|c|c|}
\hline Author & Model & Model validation & Accuracy (\%) & Specificity (\%) & Sensitivity (\%) \\
\hline Caby et al., 2011* [41] & $\begin{array}{l}\text { Radial basis function neural network, } \\
\text { support vector, } k \text {-nearest neighbour, and } \\
\text { naive Bayesian classifiers }\end{array}$ & $\begin{array}{l}\text { Leave-one-out } \\
\text { cross-validation }\end{array}$ & $75-100$ & $40-100$ & $93-100$ \\
\hline Giansanti et al., 2008*十 [48] & Multi-layer perceptron neural network & $\begin{array}{l}\text { 47:53 split } \\
\text { (Train:Test) }\end{array}$ & 97 & 97 & 98 \\
\hline Giansanti et al., 2006*+ [46] & Mahalanobis cluster analysis & $\begin{array}{l}\text { 47:53 split } \\
\text { (Train:Test) }\end{array}$ & $93.5-94.5$ & $93-94$ & 93.9-94.9 \\
\hline Giansanti et al., 2008*十 [47] & Multi-layer perceptron neural network & $\begin{array}{l}\text { 47:53 split } \\
\text { (Train:Test) }\end{array}$ & $88-91$ & $88-92$ & $88-91$ \\
\hline Gietzelt et al., 2009* [49] & Decision tree & Not specified & 90.5 & 91.0 & 89.4 \\
\hline Ganea et al., 2011* [45] & Logistic regression, ROC curve & Not specified & - & $35-88$ & $55-92$ \\
\hline Weiss et al., 2011† [74] & Logistic regression & Not specified & $63.4-87.8$ & $50.0-83.3$ & $65.2-91.3$ \\
\hline Liu et al., 2011* [57] & $\begin{array}{l}\text { Linear regression, linear discriminant } \\
\text { classifier }\end{array}$ & $\begin{array}{l}\text { Leave-one-out } \\
\text { cross-validation }\end{array}$ & 71 & 98.3 & 88.9 \\
\hline Marschollek et al., 2011‡ [61] & Logistic regression, decision tree & $\begin{array}{l}\text { Stratified ten- } \\
\text { times ten-fold } \\
\text { cross validation }\end{array}$ & $78-80$ & $82-96$ & $58-74$ \\
\hline Marschollek et al., 2008* [59] & Logistic regression, classifier & $\begin{array}{l}\text { Stratified ten- } \\
\text { times ten-fold } \\
\text { cross validation }\end{array}$ & $65.5-89.1$ & $15.4-60.4$ & $78.5-99.0$ \\
\hline Marschollek et al., 2009+ [60] & Decision tree & $\begin{array}{l}\text { Not possible due to } \\
\text { limited sample size }\end{array}$ & 90 & 100 & 57.7 \\
\hline Schwesig et al., 2012‡ [71] & Binary logistic regression, $\mathrm{ROC}$ curve & Not specified & - & $42-61$ & $63-100$ \\
\hline Moe-Nilssen et al., 2005† [65] & Linear regression, $\mathrm{ROC}$ curve & Not specified & 80 & 85 & 75 \\
\hline Bautmans et al., 2011† [40] & Logistic regression, ROC curve & Not specified & 77 & 78 & 78 \\
\hline Greene et al., 2010† [50] & Logistic regression & $\begin{array}{l}\text { 80:20 split } \\
\text { (Train:Test) }\end{array}$ & 76.8 & 75.9 & 77.3 \\
\hline Doi et al., 2013‡ [44] & Logistic regression, ROC curve & Not specified & - & 84.2 & 68.8 \\
\hline Marschollek et al., 2011‡ [62] & Logistic regression, classifier & $\begin{array}{l}\text { Stratified ten- } \\
\text { times ten-fold } \\
\text { cross validation }\end{array}$ & 70 & 78 & 58 \\
\hline Greene et al., 2012† [51] & Support vector machine & $\begin{array}{l}\text { Ten-fold cross } \\
\text { validation }\end{array}$ & 71.5 & 68.4 & 65.4 \\
\hline Kojima et al., 2008† [53] & Regression, canonical discriminant classifier & Not specified & 62.1 & 68.2 & 61.1 \\
\hline Senden et al., 2012* [72] & Linear regression, $\mathrm{ROC}$ curve & Not specified & $\begin{array}{l}\text { AUC: } 0.67- \\
0.85\end{array}$ & - & - \\
\hline
\end{tabular}


monitored. These benefits are encouraging for realworld fall risk assessment applications.

\section{Fall risk assessment models}

A wide range of sensitivity (55-100\%) and specificity (15$100 \%)$ levels have been reported for inertial-sensor-based fall risk assessment models (Table 4). The highest sensitivity and specificity levels for retrospective fall history were $91.3 \%$ and $83.3 \%$, respectively, and the highest levels using prospective fall history were $74 \%$ and $82 \%$, respectively. However, $50 \%$ of the studies did not employ separate data sets for model training and validation, thereby limiting the model's applicability beyond the training set population. Validating the model with the training population would likely result in inflated accuracy, specificity, and sensitivity levels when the model is applied to the general population compared to model validation with a different testing population. The five best performing models, in terms of overall accuracy, specificity, and sensitivity, used neural networks $[47,48]$, naive Bayesian classifier [41], Mahalanobis cluster analysis [46], and a decision tree [49]. The five worst performing models used regression [44,53,62,72] and a support vector machine [51]. Therefore, intelligent computing methods (neural networks, Bayesian classifiers, etc.) may be more appropriate for fall risk classification than regression techniques.

In the majority of papers, sensors were placed on the lower back. However, the justification for this location is limited to an intention to approximate the body center of mass and the location's unobtrusive nature for longterm use. High subject acceptance for long-term lower back sensor placement was found in a 20 day case-study by Giansanti et al., 2009 [80]. While the lower back is a promising sensor location, the upper back, hip, and thigh have potential as long-term sensor locations [81]. To date, there has been no objective evaluation to determine which sensor sites, or combinations of sites, provide the most reliable fall risk assessment. Other sensor locations, along the legs and arms, were used in predictive models with comparable sensitivity and specificity $[41,50]$. Current research has not confirmed if the total body center of gravity region is superior to other locations for fall risk identification.

Of the 13 variables that were assessed in more than one study and had significant outcomes in each study $(\mathrm{p}<0.05)$ and the six variables that had high fall risk classification sensitivity and specificity, $58 \%$ were related to postural instability and gait consistency over strides $(1-3,9-14,16,18)$. Further research is needed to corroborate these initial findings toward identifying a set of inertial-sensor-based variables that yield a robust and accurate fall risk assessment model and clinical tool.

\section{Criterion classification methods}

Clinical fall risk assessment was the predominate criterion method for classifying fallers and non-fallers when evaluating sensor-derived fall risk classification, with $32.5 \%$ of the studies using clinical assessment as the only means of classification. However, clinical assessments include false positives and false negatives that introduce inaccuracies when evaluating sensor-based systems. Another concerning aspect is that fall risk thresholds were not used consistently across research studies. For example, three studies that assessed geriatric populations devoid of neurological disorders used different TUG completiontime thresholds to determine fall risk, ranging from $11 \mathrm{~s}$ to $20 \mathrm{~s}[40,52,59]$. The literature recommends a threshold of $14 \mathrm{~s}$ for studies focused on community dwelling elderly without neurological disorders [37] and $30 \mathrm{~s}$ for community dwelling elderly with neurological disorders [82].

Retrospective fall assessment was the only criterion classification method in 30\% of the studies; however, a fall would already have occurred before the study assessment. The gait strategies and patterns during the fall may have been different from those during the assessment, because the participants could have adjusted their walking and mobility patterns to be more conservative, stable, and safe. Prospective fall occurrence is the preferred criterion classification method when placing subjects into low risk (non-faller) and high risk (faller) categories, but prospective risk was only used in 15\% of studies. Since the goal of fall risk assessment is to predict the likelihood of future falls, a prospective study that uses fall occurrence records after assessment would be more appropriate. Furthermore, prospective fall assessments have greater accuracy compared to retrospective fall assessment due to patient fall recollection issues with retrospective assessment [83].

\section{Outlook for future work}

A thorough assessment of optimal inertial sensor sites should be performed in conjunction with identification of optimal inertial-sensor-based variables, since the usefulness of a variable will likely be site specific. Better knowledge of user compliance with sensor placement at different sites will also be important when developing assessment tools that are widely accepted in the clinical and community environments. A generalized focusgroup assessment of user acceptance of wearable sensors for fall detection determined that wearable sensors would be accepted provided they were unobtrusive [84]. Only one case study demonstrated the acceptability of the lower back sensor location [80]. Therefore, larger, long-term, user compliance studies of wearable sensors are needed to ensure feasibility for fall risk assessment. If long-term compliance is an issue, sensor use may be confined to short periods in a clinical environment. 
Future studies should prospectively assess fall risk instead of relying on clinical assessments or a retrospective fall assessment, as previously discussed. Several papers emphasized the importance of using prospective fall risk occurrence in their future research [51,54,60,62,72-74], thereby avoiding the two biggest limitations of retrospective fall assessment: inaccurate recollection of fall history and gait changes due to past falls.

An important next step in this research field is to expand assessments from the geriatric population to include more specialized populations; including, those with Alzheimer's and Parkinson's diseases. Inertial sensors have the potential to identify patients with these diseases in the early stages, as suggested by Giansanti et al., 2008 [47], and identify those at risk of falling. One paper identified fallers from non-fallers in a Parkinson's Disease elderly subgroup [55]. However, more diseasespecific research is needed since optimal sensor site(s) and sensor features may be different from the generalized geriatric population. For example, arm swing may be a critical feature for people with Parkinson's Disease because reduced arm swing is one of the first presenting gait impairment features [85].

Another critical area for future work is to match predictive variables with specific fall risk factors [58]. These fall risk factors could include physical factors such as peripheral neuropathy, muscle weakness, visual impairments, reduced flexibility, and lower limb arthritis. This is a crucial step that would increase the clinical value of inertial-sensor-based fall risk assessment tools and allow identification of specific impairments that increase fall risk, thus enabling individualized treatment and intervention. The walking environment (i.e. level ground, stairs, ramps) and the activity performed (i.e. transition from sitting to standing, walking outdoors) could be associated with increased fall risk. Identification of such high-risk environments and activities may increase the accuracy of fall risk assessment [86]. Identification of specific risk factors is clinically important for preventing falls and their sequelae [79].

To demonstrate the utility of inertial-sensor-based fall risk assessments, a comparison between inertial-sensor-based assessments and current clinical assessments must be made in relation to prospective fall occurrences. This would determine whether inertial-sensor-based fall risk assessment methods alone can provide better accuracy than current clinical assessments, whether a combination of inertial sensors and current clinical assessment would optimize fall risk prediction, and if specific risk factors can be better identified when using inertial-sensor-based information. While some work has been done comparing inertial-based assessment to clinical assessments [1,50], and using a combination of inertial and clinical assessments $[60,61]$, more research in this area is required to conclusively demonstrate the advantages of inertial-based fall risk assessments.

\section{Conclusions}

Inertial sensors have the potential to provide a quantitative, objective, and reliable indication of fall risk in the geriatric population, as demonstrated in the reviewed studies. High levels of accuracy, specificity, and sensitivity have been achieved in fall risk prediction models. Future studies should identify fallers using prospective techniques and focus on determining the most promising sensor site(s), in conjunction with determination of optimally predictive variables. Further research should also investigate disease populations that are at high risk of falls and link predictive variables to specific fall risk factors, including disease-specific factors.

\section{Abbreviations}

An: Ankle; AP: Anteroposterior; AST: Alternating step test; AV: Angular velocity; COP: Center of pressure; CoV: Coefficient of variation; El: Elbow; FFT: Fast Fourier Transform; Fo: Foot; He: Head; Hi: Hip; GC: Gait cycle; Kn: Knee; LB: Lower back; ML: Mediolateral; PPA: Physiological profile assessment; ROC: Receiver operating characteristic; SD: Standard deviation; Sha: Shank; Sho: Shoulder; St: Sternum; STS: Sit-to-stand transitions; Th: Thigh; TUG: Timed Up and Go; UB: Upper back; V: Vertical; Wr: Wrist.

\section{Competing interests}

The authors declare that they have no competing interests.

\section{Authors' contributions}

$J \mathrm{H}$ reviewed the literature and drafted the manuscript with $J \mathrm{~K}$ and $\mathrm{EL}$ providing input on the manuscript content details including technical and clinical aspects. JH, JK, and EL revised and edited the manuscript. JH, JK, and EL read and approved the final manuscript.

\section{Acknowledgements}

This study was supported by the Natural Sciences and Engineering Research Council of Canada and the University of Waterloo.

\section{Author details}

${ }^{1}$ Department of Systems Design Engineering, University of Waterloo, 200 University Avenue West, Waterloo, ON N2L 3G1, Canada. ${ }^{2}$ Ottawa Hospital Research Institute, Centre for Rehabilitation, Research and Development, 505 Smyth Road, Ottawa, ON K1H 8M2, Canada. ${ }^{3}$ University of Ottawa, Faculty of Medicine, 451 Smyth Road, Ottawa, ON K1H 8M5, Canada.

Received: 2 October 2012 Accepted: 2 July 2013

Published: 8 August 2013

\section{References}

1. O'Sullivan M, Blake C, Cunningham C, Boyle G, Finucane C: Correlation of accelerometry with clinical balance tests in older fallers and non-fallers. Age Ageing 2009, 38:308-313.

2. Tinetti ME, Speechley M, Ginter SF: Risk factors for falls among elderly persons living in the community. N Engl J Med 1988, 319:1701-1707.

3. Masud T, Morris RO: Epidemiology of falls. Age Ageing 2001, 30:3-7.

4. Axer $H$, Axer M, Sauer $H$, Witte $O W$, Hagemann G: Falls and gait disorders in geriatric neurology. Clin Neurol Neurosurg 2010, 112:265-274.

5. Rao SS: Prevention of falls in older patients. Am Fam Physician 2005, 72:81-88.

6. Stevens JA, Corso PS, Finkelstein EA, Miller TR: The costs of fatal and non-fatal falls among older adults. Inj Prev 2006, 12:290-295.

7. Englander F, Hodson TJ, Terregrossa RA: Economic dimensions of slip and fall injuries. J Forensic Sci 1996, 41:733-746.

8. Hart-Hughes S, Quigley P, Bulat T, Palacios P, Scott S: An interdisciplinary approach to reducing fall risks and falls. J Rehabil 2004, 70:46-51. 
9. Canavan PK, Cahalin LP, Lowe S, Fitzpatrick D, Harris M, Plummer-D'Amato $P$ : Managing gait disorders in older persons residing in nursing homes: a review of literature. J Am Med Dir Assoc 2009, 10:230-237.

10. Maki BE, Sibley KM, Jaglal SB, Bayley M, Brooks D, Fernie GR, Flint AJ, Gage W, Liu BA, Mcllroy WE, Mihailidis A, Perry SD, Popovic MR, Pratt J, Zettel JL: Reducing fall risk by improving balance control: development, evaluation, and knowledge-translation of new approaches. J Safety Res 2011, 42:473-485.

11. Hausdorff JM, Rios DA, Edelberg HK: Gait variability and fall risk in community-living older adults: a 1-year prospective study. Arch Phys Med Rehabil 2001, 82:1050-1056.

12. Finlayson ML, Peterson EW: Falls, aging, and disability. Phys Med Rehabil Clin N Am 2010, 21:357-373.

13. Culhane KM, O'Connor M, Lyons D, Lyons GM: Accelerometers in rehabilitation medicine for older adults. Age Ageing 2005, 34:556-560.

14. Lee RYW, Carlisle AJ: Detection of falls using accelerometers and mobile phone technology. Age Ageing 2011, 40:690-696.

15. American Geriatrics Society: AGS/BGS Clinical Practice Guideline: Prevention of Falls in Older Persons. 2010 [http://www.americangeriatrics.org/health_care_ professionals/clinical_practice/clinical_guidelines_recommendations/ prevention_of_falls_summary_of_recommendations]

16. Weinstein $M$, Booth J: Preventing falls in older adults: a multifactorial approach. Home Health Care Manag and Pract 2006, 19:45-50.

17. Najafi B, Aminian K, Loew F, Blanc Y, Robert PA: Measurement of stand-sit and sit-stand transitions using a miniature gyroscope and its application in fall risk evaluation in the elderly. IEEE Trans Biomed Eng 2002, 49:843-851.

18. Cho C-Y, Kamen G: Detecting balance deficits in frequent fallers using clinical and quantitative evaluation tools. J Am Geriatr Soc 1998, 46:426-430.

19. Hahn ME, Chou L-S: Can motion of individual body segments identify dynamic instability in the elderly? Clin Biomech 2003, 18:737-744.

20. Maki BE: Biomechanical approach to quantifying anticipatory postural adjustments in the elderly. Med Bio Eng and Comput 1993, 31:355-362.

21. Nelson-Wong E, Appell R, McKay M, Nawaz H, Roth J, Sigler R, Third J, Walker M: Increased fall risk is associated with elevated co-contraction about the ankle during static balance challenges in older adults. Eur $J$ Appl Physiol 2012, 112:1379-1389.

22. Mathie MJ, Coster AC, Lovell NH, Celler BG: Accelerometry: providing an integrated, practical method for long-term, ambulatory monitoring of human movement. Physiol Meas 2004, 25:R1-R20.

23. Preece SJ, Goulermas JY, Kenney LP, Howard D, Meijer K, Crompton R: Activity identification using body-mounted sensors-a review of classification techniques. Physiol Meas 2009, 30:R1-R33.

24. Taraldsen K, Chastin SF, Riphagen II, Vereijken B, Helbostad JL: Physical activity monitoring by use of accelerometer-based body-worn sensors in older adults: a systematic literature review of current knowledge and applications. Maturitas 2012, 71:13-19.

25. Yang C-C, Hsu Y-L: A review of accelerometry-based wearable motion detectors for physical activity monitoring. Sensors 2010, 10:7772-7788.

26. Shany T, Redmond SJ, Narayanan MR, Lovell NH: Sensors-based wearable systems for monitoring of human movement and falls. IEEE Sensors $J$ 2012, 12:658-670.

27. Shany T, Redmond SJ, Marschollek M, Lovell NH: Assessing fall risk using wearable sensors: a practical discussion. Z Gerontol Geriatr 2012, 45:694-706

28. Lalkhen AG, McCluskey A: Clinical tests: sensitivity and specificity. Contin Educ in Anaesth, Crit Care and Pain 2008, 8:221-223.

29. Mahoney Fl, Barthel DW: Functional evaluation: the barthel index. Md State Med J 1965, 14:56-61.

30. Fried LP, Tangen CM, Walston J, Newman AB, Hirsch C, Gottdiener J, Seeman T, Tracy R, Kop WJ, Burke G, McBurnie MA: Frailty in older adults: evidence for a phenotype. J Gerontology: Med Sci 2001, 56A:M146-M156.

31. Honaker JA, Boismier TE, Shepard NP, Shepard NT: Fukuda stepping test: sensitivity and specificity. J Am Acad Audiol 2009, 20:311-314.

32. Mourey F, Camus A, D'Athis P, Blanchon M-A, Martin-Hunyadi C, de Rekeneire N, Pfitzenmeyer P: Mini motor test: a clinical test for rehabilitation of patients showing psychomotor disadaptation syndrome. Arch Gerontol Geriatr 2005, 40:201-211.

33. Hurvitz EA, Richardson JK, Werner RA, Ruhl AM, Dixon MR: Unipedal stance testing as an indicator of fall risk among older outpatients. Arch Phys Med Rehabil 2000, 81:587-591.
34. Guralnik JM, Simonsick EM, Ferrucci L, Glynn RJ, Berkman LF, Blazer DG, Scherr PA, Wallace RB: A short physical performance battery assessing lower-extremity function: association with self-reported disability and prediction of mortality and nursing-home admission. J of Gerontology 1994, 49:M85-M94.

35. Lord SR, Menz HB, Tiedemann A: A physiological profile approach to falls risk assessment and prevention. Phys Ther 2003, 83:237-252.

36. Oliver D, Britton M, Seed P, Martin FC, Hopper AH: Development and evaluation of evidence based risk assessment tool (STRATIFY) to predict which elderly inpatients will fall: case-control and cohort studies. Br Med J 1997, 315:1049-1053.

37. Shumway-Cook A, Brauer S, Woollacott M: Predicting the probability for falls in community-dwelling older adults using the timed up and go test. Phys Ther 2000, 80:896-903.

38. Tinetti ME, Williams TF, Mayewski R: Fall index for elderly patients based on number of chronic disabilities. Am J Med 1986, 80:429-434

39. Auvinet B, Berrut G, Touzard C, Moutel L, Collet N, Chaleil D, Barrey E: Gait abnormalities in elderly fallers. J Aging Phys Act 2003, 11:40-52.

40. Bautmans I, Jansen B, van Keymolen B, Mets T: Reliability and clinical correlates of 3D-accelerometry based gait analysis outcomes according to age and fall-risk. Gait Posture 2011, 33:366-372.

41. Caby B, Kieffer S, Hubert MS, Cremer G, Macq B: Feature extraction and selection for objective gait analysis and fall risk assessment by accelerometry. Biomed Eng Online 2011, 10:1.

42. Doheny EP, Fan CW, Foran T, Greene BR, Cunningham C, Kenny RA: An instrumented sit-to-stand used to examine differences between older fallers and non-fallers. In 33rd Annual International Conference of the IEEE EMBS: 30 August-3 September 2011. Boston; 2011:3063-3066.

43. Doheny EP, McGarth D, Greene BR, Walsh L, McKeown D, Cunningham C, Crosby L, Kenny RA, Caulfield B: Displacement of centre of mass during quiet standing assessed using accelerometry in older fallers and nonfallers. In 34th Annual International Conference of the IEEE EMBS: 28 August-1 September 2012. San Diego; 2012:3300-3303.

44. Doi T, Hirata S, Ono R, Tsutsumimoto K, Misu S, Ando H: The harmonic ratio of trunk acceleration predicts falling among older people: results of a 1-year prospective study. J Neuroeng Rehabil 2013, 10:7.

45. Ganea R, Paraschiv-lonescu A, Büla C, Rochat S, Aminian K: Multi-parametric evaluation of sit-to-stand and stand-to-sit transitions in elderly people. Med Eng and Physics 2011, 33:1086-1093.

46. Giansanti D: Investigation of fall-risk using a wearable device with accelerometers and rate gyroscopes. Physiol Measures 2006, 27:1081-1090.

47. Giansanti D, Maccioni G, Cesinaro S, Benvenuti F, Macellari V: Assessment of fall-risk by means of a neural network based on parameters assessed by a wearable device during posturography. Med Eng and Physics 2008, 30:367-372.

48. Giansanti D, Macellari V, Maccioni G: New neural network classifier of fall-risk based on the mahalanobis distance and kinematic parameters assessed by a wearable device. Physiol Measures 2008, 29:N11-N19.

49. Gietzelt M, Nemitz G, Wolf K-H, Meyer Zu Schwabedissen H, Haux R, Marschollek M: A clinical study to assess fall risk using a single waist accelerometer. Inform Health Soc Care 2009, 34:181-188.

50. Greene BR, O'Donovan A, Romero-Ortuno R, Cogan L, Scanaill CN, Kenny RA: Quantitative falls risk assessment using the timed up and go test. IEEE Trans Biomed Eng 2010, 57:2918-2926.

51. Greene BR, McGrath D, Walsh L, Doheny EP, Mckeown D, Garattini C, Cunningham C, Crosby L, Caulfield B, Kenny RA: Quantitative falls risk estimation through multi-sensor assessment of standing balance. Physiol Meas 2012, 33:2049-2063.

52. Ishigaki N, Kimura T, Usui Y, Aoki K, Narita N, Shimizu M, Hara K, Ogihara N, Nakamura K, Kato H, Ohira M, Yokokawa Y, Miyoshi K, Murakami N, Okada S, Nakamura T, Saito N: Analysis of pelvic movement in the elderly during walking using a posture monitoring system equipped with a triaxial accelerometer and a gyroscope. J Biomech 2011, 44:1788-1792.

53. Kojima M, Obuchi S, Henmi O, Ikeda N: Comparison of smoothness during gait between community dwelling elderly fallers and non-fallers using power spectrum entropy of acceleration time-series. J Phys Ther Sci 2008, 20:243-248.

54. Laessoe $U$, Hoeck HC, Simonsen $O$, Sinkjaer $T$, Voigt M: Fall risk in an active elderly population-can it be assessed? J Negat Results Biomed 2007, 6:2

55. Latt MD, Menz HB, Fung VS, Lord SR: Acceleration patterns of the head and pelvis during gait in older people with Parkinson's disease: 
a comparison of fallers and nonfallers. J Gerontology: Med Sci 2009, 64A:700-706.

56. Liu J, Lockhart TE, Jones M, Martin T: Local dynamic stability assessment of motion impaired elderly using electronic textile pants. IEEE Trans Autom Sci Eng 2008, 5:696-702.

57. Liu Y, Redmond SJ, Narayanan MR, Lovell NH: Classification between non-multiple fallers and multiple fallers using a triaxial accelerometry-based system. In 33rd Annual International Conference of IEEE EMBS: 30 August-3 September 2011. Boston; 2011:1499-1502.

58. Liu Y, Redmond SJ, Wang N, Blumenkron F, Narayanan MR, Lovell NH: Spectral analysis of accelerometry signals from a directed-routine for falls-risk estimation. IEEE Trans Biomed Eng 2011, 58:2308-2315.

59. Marschollek M, Wolf K-H, Gietzelt M, Nemitz G, Meyer Zu Schwabedissen $H$, Haux R: Assessing elderly persons' fall risk using spectral analysis on accelerometric data-a clinical evaluation study. In 30th Annual International IEEE EMBS Conference: 20-24 August 2008. Vancouver; 2008:3682-3685

60. Marschollek M, Nemitz G, Gietzelt M, Wolf KH, Wolf KH, Meyer Zu Schwabedissen $\mathrm{H}$, Haux R: Predicting in-patient falls in a geriatric clinic. Z Gerontol Geriatr 2009, 4:317-322.

61. Marschollek M, Rehwald A, Wolf K-H, Gietzelt M, Nemitz G, Meyer Zu Schwabedissen H, Haux R: Sensor-based fall risk assessment-an expert 'to go'. Methods Inf Med 2011, 50:420-426.

62. Marschollek M, Rehwald A, Wolf K-H, Gietzelt M, Nemitz G, Meyer Zu Schwabedissen H, Schulze M: Sensors vs. experts-a performance comparison of sensor-based fall risk assessment vs. conventional assessment in a sample of geriatric patients. BMC Med Inform Decis Mak 2011, 11:48

63. Martínez-Ramírez A, Lecumberri P, Gómez M, Rodriguez-Mañas L, García FJ, Izquierdo M: Frailty assessment based on wavelet analysis during quiet standing balance test. J Biomech 2011, 44:2213-2220.

64. Menz HB, Lord SR, Fitzpatrick RC: Acceleration patterns of the head and pelvis when walking are associated with risk of falling in communitydwelling older people. J of Gerontology: Med Sci 2003, 58A:446-452.

65. Moe-Nilssen R, Helbostad JL: Interstride trunk acceleration variability but not step width variability can differentiate between fit and frail older adults. Gait Posture 2005, 21:164-170.

66. Narayanan MR, Scalzi ME, Redmond SJ, Lord SR, Celler BG, Lovell NH: A wearable triaxial accelerometry system for longitudinal assessment of falls risk. In 30th Annual International IEEE EMBS Conference: 20-24 August 2008. Vancouver; 2008:2840-2843.

67. Narayanan MR, Scalzi ME, Redmond SJ, Lord SR, Celler BG, Lovell NH: Evaluation of functional deficits and falls risk in the elderly-methods for preventing falls. In 31st Annual International Conference of the IEEE EMBS: 2-6 September 2009. Minneapolis; 2009:6179-6182.

68. Narayanan MR, Redmond SJ, Scalzi ME, Lord SR, Celler BG, Lovell NH: Longitudinal falls-risk estimation using triaxial accelerometry. IEEE Trans Biomed Eng 2010, 57:534-541

69. Paterson K, Hill K, Lythgo N: Stride dynamics, gait variability and prospective falls risk in active community dwelling older women. Gait Posture 2011, 33:251-255.

70. Redmond SJ, Scalzi ME, Narayanan MR, Lord SR, Cerutti S, Lovell NH: Automatic segmentation of triaxial accelerometry signals for falls risk estimation. In $32^{\text {nd }}$ Annual International Conference of the IEEE EMBS: August 31-September 4 2010. Buenos Aires; 2010:2234-2237.

71. Schwesig R, Fischer D, Lauenroth A, Becker S, Leuchte S: Can falls be predicted with gait analytical and posturographic measurement systems? a prospective follow-up study in a nursing home population. Clin Rehabil 2013, 27:183-190.

72. Senden R, Savelberg HH, Grimm B, Heyligers IC, Meijer K: Accelerometrybased gait analysis, an additional objective approach to screen subjects at risk for falling. Gait Posture 2012, 36:296-300.

73. Toebes MJP, Hoozemans MJ, Furrer R, Dekker J, van Dieën JH: Local dynamic stability and variability of gait are associated with fall history in elderly subjects. Gait Posture 2012, 36:527-531.

74. Weiss A, Herman T, Plotnik M, Brozgol M, Giladi N, Hausdorff JM: An instrumented timed up and go: the added value of an accelerometer for identifying fall risk in idiopathic fallers. Physiol Measures 2011, 32:2003-2018

75. Yack HJ, Berger RC: Dynamic stability in the elderly: identifying a possible measure. J of Gerontology: Med Sci 1993, 48:M225-M230.
76. Webster JG: The measurement, instrumentation, and sensors handbook. Florida: CRC Press LLC; 1999.

77. Martin FC: Falls risk factors: assessment and management to prevent falls and fractures. Can J Aging 2011, 30:33-44.

78. Prince F, Corriveau H, Hébert R, Winter DA: Gait in the elderly. Gait Posture 1997, 5:128-135.

79. Maki BE: Gait changes in older adults: predictors of falls or indicators of fear? J Am Geriatr Soc 1997, 45:313-320.

80. Giansanti D, Morelli S, Maccioni G, Constantini G: Toward the design of a wearable system for fall-risk detection in telerehabilitation. Telemed e-Health 2009, 15:296-299.

81. Gemperle F: Design for wearability. Pittsburgh: Second International Symposium on Wearable Computers; 1998:116-122.

82. Podsiadlo D, Richardson S: The timed "Up and Go": a test of basic functional mobility for frail elderly persons. J Am Geriatr Soc 1991, 39:142-148.

83. Ganz DA, Higashi T, Rubenstein LZ: Monitoring falls in cohort studies of community-dwelling older people: effect of the recall interval. $J \mathrm{Am}$ Geriatr Soc 2005, 53:2190-2194.

84. Gövercin M, Költzsch Y, Meis M, Wegel S, Gietzelt M, Spehr J, Winkelbach S, Marschollek M, Steinhagen-Thiessen E: Defining the user requirements for wearable and optical fall prediction and fall detection devices for home use. Inform Health Soc Care 2010, 35:177-187.

85. Cole MH, Silburn PA, Wood JM, Worringham CJ, Kerr GK: Falls in Parkinson's disease: kinematic evidence for impaired head and trunk control. Mov Disord 2010, 25:2369-2378.

86. Wu HH, Lemaire ED, Baddour N: Activity change-of-state identification using a blackberry smartphone. J Med and Biol Eng 2012, 32:265-272.

doi:10.1186/1743-0003-10-91

Cite this article as: Howcroft et al:: Review of fall risk assessment in geriatric populations using inertial sensors. Journal of NeuroEngineering and Rehabilitation 2013 10:91.

\section{Submit your next manuscript to BioMed Central and take full advantage of:}

- Convenient online submission

- Thorough peer review

- No space constraints or color figure charges

- Immediate publication on acceptance

- Inclusion in PubMed, CAS, Scopus and Google Scholar

- Research which is freely available for redistribution 